\title{
O LATIM NA FACULDADE DE LETRAS
}

Johnny José Mafra

UFMG / PUC Minas

\begin{abstract}
Quando escasseiam os registros documentais, costumamos instituir em monumento a memória viva dos que, vencendo o tempo, conservam a lembrança de feitos passados e oportunamente os atualizam para que a geração em curso preserve os elos que interligam passado e presente. É desse teor o projeto da Revista Aletria, no ensejo desta edição comemorativa de datas e feitos relevantes. Convidado a participar desse projeto, minha contribuição consistirá num esforço de memória para atualizar dados sobre os estudos de língua latina na Faculdade de Letras. A tarefa é gratificante, pois traz à lembrança uma trajetória pessoal iniciada na quase adolescência, quando dos primeiros estudos acadêmicos no curso de Letras Clássicas da antiga Faculdade de Filosofia da UMG, predecessora da atual Faculdade de Letras da UFMG.

Remonto aos idos de 1958 e, ao fazê-lo, assumo o risco de me perder entre o verdadeiro e o verossímil, fato que não estranho, pois, penso, assim se faz a história.

Os estudos latinos, tais como existem hoje na Faculdade de Letras, tiveram dois inícios: um em 1939, data da criação da Faculdade de Filosofia, outro em 1968, quando o curso de Letras foi transformado em Faculdade de Letras, conforme a Lei 5.540/68, que trata da reforma universitária.

Uma vez criada a Faculdade de Filosofia, em 1939, pelo então Ministro da Educação e Cultura Gustavo Capanema, foi instituída a Cátedra de Latim e indicado Catedrático o professor José Lourenço de Oliveira, de já longa história nos domínios do Latim e há pouco bacharelado nas ciências jurídicas na própria Universidade.

Desses primórdios guardo uma lembrança de oitiva, pois à época da minha entrada, em 1958, vários professores já não pertenciam aos quadros da Faculdade, como o professor Cláudio Brandão, catedrático de grego, afastado por doença, e o professor Arduíno Bolivar, catedrático de literatura latina, falecido em 1954. Deste sei que gozava de grande estima de professores e alunos e que, por isso e por sua influência nos estudos latinos, decidiu-se nomear "Arduíno Bolivar" ao Instituto de Humanidades, criado em 1955 com o objetivo de "estudar as humanidades na sua expressão mediterrânea, isto é, grega, latina e neolatina”. (art. 2o do Regimento)

O ingresso no curso de Letras Clássicas dava-se por um exame vestibular composto de provas escritas e orais de Latim, Português e Francês, prática conservada até as mudanças de 1968. No tocante ao Latim, o candidato deveria demonstrar competência para tradução de trechos selecionados do livro Tristia, de Ovídio, e para tradução e análise linguística de trecho sorteado da Primeira Catilinária (In Catilinam Oratio Prima), de Cícero. Submeti-me a essa sabatina, tendo sido examinado pelos professores José Lourenço de Oliveira e Rubens Costa Romanelli.
\end{abstract}


Nessa época, o curso de Letras Clássicas era constituído por três cátedras, a de Língua Latina, a de Literatura Latina e a de Língua e Literatura Grega, além, é certo, das cátedras de Língua Portuguesa, Literatura Brasileira e Literatura Portuguesa.

Ocupavam a cátedra de Latim os professores José Lourenço de Oliveira (catedrático), Rubens Costa Romanelli e Cônego Francisco Bueno de Sequeira (adjuntos); a cátedra de Literatura Latina, vaga com a morte do professor Arduíno Bolivar, foi ocupada pelo professor José Altimiras até a posse, no segundo semestre de 1958, da professora Aída Costa, nomeada após concurso de títulos, prova escrita e defesa de tese, de que participara o próprio professor Altimiras.

A Cátedra era uma instituição acadêmica, como uma célula administrativa com autonomia didático-pedagógica, cujo ocupante, o Catedrático, detinha poderes absolutos sobre a sua área, como, entre outros, o de determinar programas, impor linhas de pesquisa e indicar, para a competente nomeação, após exame denominado Venia legendi, os seus auxiliares. A cátedra era vitalícia, isto é, o catedrático, uma vez investido no cargo, deixava-o somente em razão de aposentadoria ou de morte.

Memoráveis as aulas de latim, dos primórdios até os anos 1960, ministradas por Lourenço e Romanelli. A Faculdade, tendo ocupado inicialmente as instalações da Casa d'Italia e do Instituto de Educação, funcionava, a esses tempos, em sede própria, nos andares 18, 19 e 20 do Edifício Acaiaca, na avenida Afonso Pena, centro de Belo Horizonte. Era aí, no 18o andar, que assistíamos às aulas de Latim. O Catedrático desenvolvia lições de linguística latina e seu adjunto acompanhava-o com a tradução de textos arcaicos de Névio e Ênio e competentes lições de gramática, com ênfase na morfologia, na fonética e na etimologia. Dois professores, dois modi operandi na condução do ensino. Romanelli, a caminho de uma didática nova, impunha-se pela relação fácil com os alunos, o que resultava em entusiasmo e grande gosto pelo Latim; Lourenço, autoritário, de riso contido, austero, era visto por muitos como representante de uma "velha escola", que os estudantes já não mais aceitavam. Ele impunha um certo medo, como comenta Ana Lúcia Gazzola em José Lourenço de Oliveira: legado e testemunhos (p. 19). Alguns alunos o consideravam "quadradão", mas o respeitavam e ele se fazia respeitar por sua "postura correta e justa, incapaz de qualquer favoritismo ou menosprezo".

Fez história na Faculdade a aula de Latim do professor Lourenço. Iniciava-se esta às sete horas da manhã, e os alunos, com razoável pontualidade, cumpriam o horário. $\mathrm{O}$ professor, porém, não por afoiteza, mas por hábito e rigor de método, chegava às seis horas, de modo que, às sete, já tinha posto no quadro-negro (ou na "pedra", como ele dizia) a sua matéria: o texto latino (tirado da primeira "Catilinária"), fundamentos teóricos e análise binomial de cada frase do texto. À chegada dos alunos, o professor iniciava a demonstração, em diagrama, das funções sintagmáticas estudadas na sua relação binomial. A esse método ele chamava "análise binomial" ou "análise diagramática". Vencendo a austeridade do professor, que se emocionava com a aproximação, muitos alunos se punham ao seu redor, de pé, junto do quadro, e discutiam, como se iguais fossem, a difícil relação por ele chamada de parataxe, hipotaxe, metataxe.

Foi marcante a atuação dos dois mestres, Lourenço e Romanelli, na implantação de altos estudos da linguística latina, a par do Latim conhecido e corrente nas escolas, na igreja, na lide forense ou na sociedade culta. Os alunos, que já dominavam a língua 
pelos métodos Ragon, Ravizza, dentre outros, em pouco tinham em mãos os linguistas europeus dos fins do século XIX e inícios do século XX, Ernout, Meillet, Vendryès, Benveniste, Saussure etc.

As lições de língua latina completavam-se com as de literatura latina, privilégio daqueles que cursavam Letras Clássicas. Aída Costa, que sucedeu a Arduíno Bolivar na cátedra ocupada temporariamente por José Altimiras, imprimiu nova dinâmica e novos métodos ao estudo da literatura. Dividia seu curso em duas partes, curso propedêutico e curso monográfico, e ela própria se dividia entre as lições de teoria literária e iniciação à literatura latina e a leitura e análise dos autores latinos. Assim é que o teatro de Plauto, Terêncio e Sêneca, a epopéia vergiliana e a grande lírica de herança helênica que celebrizou os poetas Catulo, Horácio, Vergílio, Ovídio, Tibulo, entre muitos outros, enriqueceram a visão de mundo dos alunos e marcaram ponto na alta qualificação dos estudos latinos na Faculdade.

$\mathrm{Na}$ sequência dos tempos, outros professores procedentes da própria Faculdade completaram o corpo docente do curso de Letras Clássicas. Apenas para registro, foram eles, até a a década de 80: Antônio Salles, Oscarino da Silva Ivo, Johnny José Mafra, Olinto Carlos da Fonseca, Padre Geraldo Alves, Vicente de Paulo Iannini, João Carlos de Mello Mota, Daniel de Carvalho Gonçalves e Antônio Martinez de Rezende.

Promulgada a Lei 5.540/68 da Reforma Universitária, desmembrou-se da Faculdade de Filosofia o Curso de Letras, constituído em unidade autônoma com a denominação de Faculdade de Letras da UFMG, com nova configuração administrativa e didáticopedagógica. O ponto relevante dessa reorganização foi a extinção da cátedra vitalícia e a criação de uma carreira docente composta de cargos não hierárquicos, denominados titular, adjunto, assistente e auxiliar. A cátedra passou a ser apenas uma das disciplinas do currículo e os catedráticos passaram a professores titulares.

Nesse cenário de 1968, estando já a Faculdade na nova sede da rua Carangola, bairro Santo Antônio, deu-se o segundo início dos estudos de Latim no curso de Letras, agora transformado em Faculdade de Letras. Deixou de existir a Cátedra de Latim, que passou a disciplina ministrada por professores titulares, adjuntos, assistentes ou auxiliares. Tal mudança não acarretou prejuízos para os conteúdos nem para a qualidade dos estudos, pois uma nova geração de docentes se desenvolvia a partir de então, sendo os professores qualificados nos cursos de Mestrado e Doutorado instituídos de acordo com a Lei 5.540. Dessa geração, fruto do grande esforço e do alto padrão dos estudos implantados por Lourenço, Romanelli, Aída Costa e seus auxiliares, resulta o atual corpo docente do curso de Latim da Faculdade de Letras que, valendo-se de todos os instrumentos que lhes facultam os novos tempos, mantêm em alta a qualidade dos estudos da língua e da literatura latina.

Do Latim e dos professores, da Faculdade e da convivência dos colegas, resta uma agradável memória que, passado o tempo, faz parte de uma história que a mente traz à colação. São feitos e momentos de um passado que, vez ou outra, agrada relembrar, tal como diz o vate de Mântua na Eneida, I, 203: "Haec olim meminisse iuvabit". Dará gosto um dia relembrar essas coisas. 